\title{
Analysis
}

\section{Rethinking role models in general practice}

\section{WHAT ARE ROLE MODELS AND WHY ARE THEY IMPORTANT TO THE FUTURE OF GENERAL PRACTICE?}

Role models have traditionally been seen as more senior professionals who are perceived as exemplary and worthy of imitation. They influence and teach by example and are an aspect of our culture that we easily take for granted. They are timeless, and healthy societies throughout history have depended on them. Osler adopted role models from an early age, under whose influence he developed a passion for natural history and a discipline of scrupulous observation. The General Medical Council states:

Doctors who train other doctors are critical to developing and improving standards of care - they help shape the next generation of doctors and are important role models for medical students and doctors in training. "1

This process of observation, emulation, experimentation, and assimilation is vital for the development of generalist expertise. However, role models have received less attention than the other two essential elements of effective medical education: organised teaching and structured experiences.

Role models are of great importance in all education and complement the explicit mentorship relationship GP trainers have with their trainee when they ask questions and give advice. ${ }^{2}$ The trainer-trainee relationship is probably the most important single variable affecting a trainee's progress. Observation allows the trainee to ask, "What would X do?' This holds true for important areas of practice such as prescribing. Albert Bandura, an influential professor of psychology at Stanford wrote:

Learning would be exceedingly laborious, not to mention hazardous, if people had to rely solely on the effects of their own actions to inform them what to do. Fortunately, most human behaviour is learned observationally through modelling: from observing others one forms an idea of how new behaviours are

\section{"The culture of our practices will act to facilitate or hinder effective role modelling.}

performed, and on later occasions this coded information serves as a guide for action. ${ }^{3}$

Used effectively role models can help students and trainees make sense of, engage with, and take action towards developing generalist expertise.

\section{ATTRIBUTES OF ROLE MODELLING THAT ARE VITAL IN GENERAL PRACTICE}

A study of the characteristics of excellent role models showed them to stress the importance of the doctor-patient relationship in their teaching. ${ }^{4}$ They concluded that many of their attributes are related to skills that can be acquired. Highly regarded physician role models described 'role-modeling consciousness', that is, they specifically think about being role models when interacting with learners. ${ }^{4}$ When asked, their personal qualities included a positive outlook, a commitment to excellence and growth, integrity, and leadership. As teachers they aspired to establishing rapport with learners. ${ }^{4}$

\section{Professional judgement}

Judgement requires the garnering of information and then making judicious decisions; this lies at the heart of what it means to be professional. Generalists who frequently deal with the more sensitive facets and nuances of a patient's life must exercise the virtues more diligently than techniqueoriented specialists. The narrower the specialty, the more easily the patient's good can be safeguarded by rules, regulations, rights and duties; the broader the specialty, the more significant are the physician's character traits.

\section{Service delivery}

Our performance as role models is unlikely to improve without conscious thought and action. ${ }^{4}$ The culture of our practices will act to facilitate or hinder effective role modelling. In poor organisations staggering from crisis to crisis, trainees will absorb weak interpersonal relationships between professionals, a blame culture, and overconcern with money. Derogatory and cynical humour have a pernicious effect, and leaders need to lead by not acquiescing in cynicism directed at others. ${ }^{5}$

In all professional organisations the senior and most influential staff tend to set the tone for the organisation. ${ }^{6}$ The recent decline in popularity of GP partnerships, rise in portfolio careers, and emergence of primary care networks presents new challenges, changing traditionally held views of what constitutes a role model. So we might ask whether the environment for which we are responsible supports or hinders positive role modelling? In demonstrating genuine interest in others we show that it is unnecessary to be inward looking, but rather enjoy the glorious sense of purpose that comes out of doing things for others rather than oneself:"

\section{HOW MIGHT GPS MOST EFFECTIVELY SERVE AS ROLE MODELS TO THOSE AT DIFFERENT STAGES? \\ Undergraduate medical education}

There are numerous references to role models' in the medical educational literature with predominantly medical students being the principal subjects of research. Role models have a major influence in their acquisition of professional qualities and choice of career, playing an important role in shaping hidden curricula. GPs interacting with students on placements are the most influential group on students' perceptions of general practice, with $81 \%$ of students reporting that this group had influenced their perceptions most. ${ }^{8}$ This supports recent calls for positive and enthusiastic GP role models to be identified and made visible across all medical schools. ${ }^{9}$ We need to question 'who' constitutes a role model given the growing awareness that 'near peers' such as GP trainees and early-career GPs can also serve as effective role models. The shift away from 


\section{"In the context of medical generalism role models have a particular value in guiding patient-centred care...}

traditional medical school curricula to more blended approaches with more time spent in primary care provides opportunities to achieve this.

\section{Postgraduate medical education}

At the postgraduate level there are few studies of role models in general practice. ${ }^{10}$ Outside of general practice Passi et al found:

. a consistent picture from across the world of three groups of attributes demonstrated by effective role models - namely high standards of clinical competence, good teaching ability and a set of personal attributes that transmit professionalism."10

A study of female doctors at different career stages reported how important they are for inspiring, boosting confidence, and providing support. ${ }^{11}$

\section{PEER-TO-PEER ROLE MODELLING AMONG GENERALISTS}

In the context of medical generalism role models have a particular value in guiding patient-centred care and tolerating uncertainty. Negative role models have been found to be less patient centred. ${ }^{10}$ Pellegrino highlighted the virtue of balancing conflicting obligations judiciously:

'In a pluralistic society we need laws, rules and principles to assure a dependable minimum level of moral conduct. But that minimum level is insufficient in the complex and often unpredictable circumstances of decision-making, where technical and value desiderata intersect so inextricably. ${ }^{12}$

This mayaccount for many of the limitations experienced in relation to guidelines and protocols in generalist practice.

\section{THE ROLE OF THE COLLEGE IN RECOGNISING AND PROMOTING ROLE MODELS}

Initiatives such as the First5 scheme have heavily advocated peer support and mentorship but failed to fully utilise role models within the mentoring spectrum. This is important especially at a time when social media may be challenging our traditional understanding of how role models are formed, chosen, and the possibility to interact with them. There is evidence to suggest that having role models in one's online social network may boost the user's future oriented engagement.

Current guidance on Fellowship of the Royal College of General Practitioners does not specifically mention the value of positive role models, though this is being reviewed as part of a broader review of criteria for Fellowship. In contrast, College initiatives such as 'Destination GP' have highlighted the power of positive near-peer role models and the impact this can have on career choices. ${ }^{8}$ What role models uniquely do in medical education is embody professional characteristics. Enthusiasm for one's work was the most highly regarded attribute of physicians selected as role models by medical students with the level of passion we display for our job being a compelling factor. ${ }^{10}$

\section{CONCLUSION}

There remains much more for us to learn about the complex phenomenon of role modelling. Role models can be thought to add colour to the monochrome picture of what to do in medicine by showing how it can be done. This requires sufficient closeness to see them in action with patients actually doing the job rather than merely describing it. Role modelling is most effective when there is an ongoing and close relationship so individualised career support and encouragement can continue to be given. They are essential but untapped to the extent that they are inescapable but not forgotten.

\section{John Holden,}

GP, Garswood Surgery, Wigan.

\section{Stephen Cox,}

GP and Visiting Professor, University of Chester, Chester.

\section{Greg Irving,}

GP and Clinical Lecturer, University of Cambridge, Cambridge.

\section{Provenance}

Freely submitted; externally peer reviewed.

\section{Acknowledgements}

The late John Holden, a true GP role model to many,

\section{ADDRESS FOR CORRESPONDENCE}

Greg Irving

University of Cambridge, Institute of Public Health and Primary Care, Forvie Site, Cambridge CB23 OSR, UK.

\section{Email: greg_irvinglahotmail.com}

sadly died while writing this paper. John was a role model to both Greg and Steve, influencing directly in professional meetings, in researching publications, and in informal group discussions. We would also like to thank Andrew Rudge for commenting on the article from a patient perspective and Professor Amanda Howe for her comments.

DOI: https://doi.org/10.3399/bjgp20X712517

\section{REFERENCES}

1. General Medical Council. Duties of a doctor in the workplace. https://www.gmc-uk.org/ ethical-guidance/ethical-guidance-for-doctors/ leadership-and-management-for-all-doctors/ duties-of-a-doctor-in-the-workplace laccessed 4 Aug 2020).

2. Cruess SR, Cruess RL, Steinert Y. Role modelling - making the most of a powerful teaching strategy. BMJ 2008; 336(7646): 718-721

3. Bandura A. Social learning theory. New York, NY: General Learning Press, 1977.

4. Wright SM, Wong A, Newill C. The impact of role models on medical students. J Gen Intern Med 1997; 12(1): 53-56.

5. Wear D, Aultman JM, Varley JD, Zarconi J. Making fun of patients: medical students perceptions and use of derogatory and cynical humor in clinical settings. Acad Med 2006; 81(5): 454-462.

6. Dale S, Olds J. Maintaining professionalism in the face of burnout. Br J Gen Pract 2012 62(604): 605-607.

7. Neuberger JB. Unkind, risk averse and untrusting: if this is today's society, can we change it? In: Utting D, ed. Contemporary social evils. Bristol: Policy Press, 2009: 114-124.

8. Royal College of General Practitioners Destination GP: medical students' experiences and perceptions of general practice. 2017. https://www.rcgp.org.uk/policy/rcgp-policy areas/destination-gp.aspx laccessed 4 Aug 2020).

9. Wass V, Gregory S, Petty-Saphon K. By choice - not by chance: supporting medical students towards future careers in general practice. London: Health Education England, 2016.

10. Passi V, Johnson S, Peile E, et al. Doctor role modelling in medical education: BEME Guide No. 27. Med Teach 2013; 35(9): e1422-e1436.

11. Peters K, Ryan M, Toppin E, et al. The role models who sustain medical women's career engagement. Who do they need to be, and what do they need to do? London: Women's Medical Foundation, 2014

12. Pellegrino ED. The virtuous physician and the ethics of medicine. In: Shelp EE, ed. Virtue and medicine: exploration in the character of medicine. Dordrecht: D Reidel, 1985: 237-255. 